\title{
A SPORADIC CASE OF TYPHOID FEVER
}

\author{
Lieutenant-Colonel J. D. CORMACK, M.B., F.R.C.P.E., R.A.M.C. \\ British Military Hospital, Singapore
}

SUMMARY: A sporadic case of typhoid fever is described and treatment discussed. This case appears unconnected with the scattering of cases reported during the summer of 1969 from the Tunisian outbreak and other holiday resorts around the Mediterranean. The initial period of the illness lacks very distinctive features and the presentation may suggest a ' virus infection'. Sporadic cases can be diagnosed and perhaps lives saved if awareness of the possibility of typhoid fever is kept in mind and cases presenting as pyrexia of unknown origin are adequately screened. This case is reported as a reminder of the importance of this principle.

\section{Introduction}

On the 8th September 1969, Gunner S. aged 20 years; was admitted to the British Military Hospital, Rinteln, with a three to four day. history of frontal headache, slight photophobia, fever and a slight non-productive cough. There were no significant previous illnesses. His mother, now 47 years of age, was under treatment for Addison's disease. The patient had no pets or unusual hobbies. He smoked 20 cigarettes per day, but drank beer only intermittently and not to excess. For the preceeding three months he had lived in barracks at Gutersloh. On being questioned as to his eating habits, he stated that he very seldom ate outside the camp, but when doing so was always in the company of two particular friends. These friends have remained well. Three months earlier he had been on a training scheme in Canada. He had not been on leave elsewhere as it was his intention to get married in December 1969 and he was saving his leave entitlement.

\section{Clinical examination}

Clinical examination on admission confirmed the presence of fever but was otherwise unhelpful. Repeated-examination did not add any helpful information until 14th September (the tenth day of illness) when the spleen became palpable, The abdomen about this time started to develop a 'doughy' feel. No rose spot rash was noted.

\section{Case history}

During the initial period of hospitalisation repeated urine examinations had revealed no abnormality. The initial Erythrocyte sedimentation rate (E.S.R.) was $25 \mathrm{~mm}$ in one hour, the haemoglobin level being $13.2 \mathrm{~g} / 100 \mathrm{ml}$ and the total white cell count (W.B.C.) was 5,900/cu mm with a normal differential count and film. Subsequently the W.B.C. fell to around $4,000 / \mathrm{cu} \mathrm{mm}$ with polymorphonuclear cells reduced to 47 per cent. The haemoglobin fell to $10.9 \mathrm{~g} / 100 \mathrm{ml}$. A throat swab had revealed no pathogens or smear on culture examination. Electrolytes, blood urea and liver function tests were undisturbed. X-rays of the chest nasal sinuses and a check of the teeth revealed no abnormality. An intravenous pyelogram had also been carried out with normal results. The Paul Bunnell screening test was negative on two occasions. The Venereal Disease Research Laboratory (V.D.R.L.) test was also negative. Screening tests against Brucella melitensis and abortus were 1:10 or less. The Weil Felix was the sole, immediately 
available, screening test against rickettsial infection; this was negative at $\mathrm{OX}_{2}-1: 40$; $\mathrm{OX}_{19}-<1: 10$ and $\mathrm{OXK}-1: 80$.

The Widal reaction on the eighth day of the illness and the fifteenth day of the illness was reported as

Vi.

S. typhi ' $\mathrm{O}$ ', $1: 160$

S. paratyphi A ' $\mathrm{O}$ ' $<1: 10$

S. paratyphi $\mathrm{B}^{\text {' }} \mathrm{O} \mathrm{O}^{\prime} \quad<1: 10$

S. paratyphi C ' $\mathrm{O}$ ' $<1: 20$

Vi.

S. typhi ' $\mathrm{O}$ '

\section{Eighth day}

S. typhi ' $H$ '

S. paratyphi A ' $\mathrm{H}, \quad 1: 40$

S. paratyphi $B$ ' $H$ ' , $, 1: 40$

S. paratyphi C' $\mathrm{H}$ ' $\quad 1: 40$

Fifteenth day

The blood cultures taken on the eleventh and twelfth day of the illness resulted in the isolation of Salmonella typhi. The organism was also grown from a stool culture at this time and was fully sensitive in the laboratory to chloramphenicol and ampicillin.

Empirically while awaiting the results of investigations, he had been started on ampicillin $500 \mathrm{mg} 6$ hourly and he received this for forty-eight hours before commencing chloramphenicol $2 \mathrm{~g}$ daily. There was no discernable response to ampicillin and improvement with lessened toxaemia was not clinically evident until after fifty-six hours of chloramphenicol treatment. The fever became intermittent on the third day of this treatment. On the fifth day the pulse was clearly settling, but it was the eleventh day of treatment before he was afebrile for twenty-four hours. The chloramphenicol was continued from this stage at a dosage of one gramme daily to a total of sixteen days treatment. Clinical well-being continued to improve and his weight rose steadily. He tolerated a fuller, and then, normal diet and was fully mobilised over a further three week period before proceeding on convalescent leave. Clearance stools were obtained over this period and S. typhi could not be isolated. Twenty-four hour specimens of urine were also sterile.

\section{Comment}

Extensive investigations by the Assistant Director of Army Health, Headquarters 2 Division in collaboration with the German Medical Officers of Health failed to uncover the source of this patient's infection. It is of interest to record that the German Medical Officer of Health for Gutersloh was able to report that another sporadic case had occurred in June 1969 in a German national living within two miles of the Barracks. 